\title{
The evolving concept of liver cancer stem cells
}

\author{
Kouki Nio ${ }^{1,2}$, Taro Yamashita ${ }^{2^{*}}$ and Shuichi Kaneko ${ }^{2}$
}

\begin{abstract}
Liver cancer is an often fatal malignant tumor with a high recurrence rate and chemoresistance. The major malignant phenotypes of cancer, including recurrence, metastasis, and chemoresistance, are related to the presence of cancer stem cells (CSCs). In the past few decades, CSCs have been identified and characterized in many tumors including liver cancer. Accumulated evidence has revealed many aspects of the biological behavior of liver CSCs and the mechanism of their regulation. Based on these findings, a number of studies have investigated eradication of liver CSCs. This review focuses on the recent advances in our understanding of the biology of liver CSCs and the development of strategies for their treatment.
\end{abstract}

Keywords: Liver cancer, Cancer stem cell, Niche, Chemoresistance

\section{Background}

Liver cancer is one of the most common cancers worldwide and has a high mortality rate [1,2]. Among primary liver cancers, hepatocellular carcinoma (HCC) is the major histological subtype and accounts for $70-85 \%$ of total liver cancer cases [1]. When diagnosed at an early stage, patients generally undergo surgical resection or liver transplantation according to their hepatic reserve. However, liver cancer is often difficult to treat surgically because many cases are diagnosed at an advanced stage, even at the time of initial diagnosis. Even after surgical treatment, liver cancer recurs frequently and metastasizes. Although chemotherapy, including molecular targeting therapy, is a treatment option for patients with advanced liver cancer, its therapeutic effects are limited, resulting in poor overall survival. The development of cancer recurrence, metastasis, and chemo- and radioresistance in a solid tumor is attributed to the presence of cancer stem cells (CSCs) [3]. In liver cancer, accumulating evidence has demonstrated the existence of a small subset of cancer cells with stem cell properties (self-renewal and differentiation) and several CSC markers have been identified, including CD133, CD90, CD44, oval cell marker OV6, EpCAM, CD13, CD24, DLK1, $\alpha 2 \delta 1$,

\footnotetext{
* Correspondence: taroy@m-kanazawa.jp

2Department of Gastroenterology, Kanazawa University Graduate School of Medical Science, 13-1 Takara-Machi, 920-8641 Kanazawa, Ishikawa, Japan Full list of author information is available at the end of the article
}

ICAM-1, CD47, Lgr5, and keratin19 [4-16]. At present, liver CSCs are considered an important targeting subset for the successful treatment of liver cancer. In this review, we summarize the current understanding of the biology of liver CSCs and recent advances in their clinical diagnosis and treatment.

The hierarchical CSC concept and the origin of liver CSCs Phenotypic and functional tumor heterogeneity, which is observed in many tumors including liver cancer [17-19], can arise through stochastic genetic [17] or epigenetic [20] changes, or in response to extrinsic environmental differences [21], or from the hierarchical organization of CSCs [22, 23]. In the hierarchical CSC concept, which was first proposed in the 1970s [24], CSCs are present in the biological hierarchy of cancer and have the capacity of self-renewal, multi-lineage potency, and extensive proliferation, resulting in the presence of heterogeneous cells within a tumor. Even though the existence of liver CSCs has been explored by the identification of several surface markers in freshly resected HCC specimens using antibodies and/or flow cytometry-based cell separation methods, their origin remains to be determined $[25,26]$.

The transformation of liver stem/progenitor cells has been considered one possible origin of liver CSCs. Indeed, CSCs share similar features with normal stem cells, for example, self-renewal and pluripotency, and liver CSCs 
are identified and classified using normal liver stem/ progenitor cell markers, such as EpCAM [27], Lgr5 [28], CD133 [29], and CD24 [30]. Many types of liver cancer develop as a result of a long-lasting inflammation/ regeneration process that is induced by chronic viral infection (e.g., hepatitis B virus [HBV]/hepatitis $\mathrm{C}$ virus $[\mathrm{HCV}])$, alcohol, or non-alcoholic fatty liver disease. In this process, the expansion of stem/progenitor cells, accumulation of genetic and/or epigenetic changes, and alteration of the microenvironment occur continuously, resulting in the initiation and/or promotion of liver cancer [31]. Furthermore, this process might facilitate the transformation of hepatic stem/progenitor cells into liver CSCs [32-34].

However, liver CSCs do not necessarily originate from only transformed normal stem/progenitor cells, Various cell types, including mature hepatocytes and biliary cells, can be a source of hepatocytes by initializing stem cells during liver regeneration [35]. This initializing process implies another possible origin of CSCs; namely, differentiated cells might be transformed into CSCs due to genetic/epigenetic alteration during cell initialization in the liver injury/regeneration process. Holczbauer et al. investigated the ability of distinct differentiated hepatic lineage cells to acquire CSC properties by stable cotransduction of oncogenic H-Ras/SV40LT into murine hepatic progenitor cells, hepatoblasts, and adult hepatocytes. They found that all transduced hepatic lineage cells can be reprogrammed into CSCs by genetic/epigenetic alterations [36].
Moreover, CSCs may originate from non-CSCs by the activation of "dedifferentiation" [31]. In fact, some evidence of the dedifferentiation of mature cells into CSCs has been accumulated in solid cancer [37, 38]. Recently, Liu et al. reported that the chromatin remodeling factor CHD1L promotes the dedifferentiation of HCC and confers stem cell-like properties on these cells by opening chromatin [39].

These findings imply that stem/progenitor cells, mature parenchymal cells, and differentiated liver cancer could be the origin of liver CSCs via "transformation," "cell initialization," and "dedifferentiation," respectively (Fig. 1).

Intrahepatic cholangiocarcinoma (ICC) is the second most frequent histological subtype in liver cancer and is also a treatment refractory malignancy with a high mortality. Originally, ICC has been thought to derive from malignant transformation of mature cholangiocytes composing intrahepatic bile ducts. Interestingly, however, two independent groups demonstrated using cell fate lineage tracing in mice that ICC arises from hepatocytes, rather than cholangiocytes or hepatic stem/progenitors, through Notch/Akt-mediated conversion of hepatocytes into biliary lineage cells $[40,41]$. This finding might provide some insights considering "cell reprogramming" related to hepatic stem cell lineage and carcinogenesis.

\section{Cell surface markers and their function in liver CSCs}

Since the first evidence of CSCs in acute myeloid leukemia [42], the existence of CSCs and the identification of CSC cell surface markers have been investigated
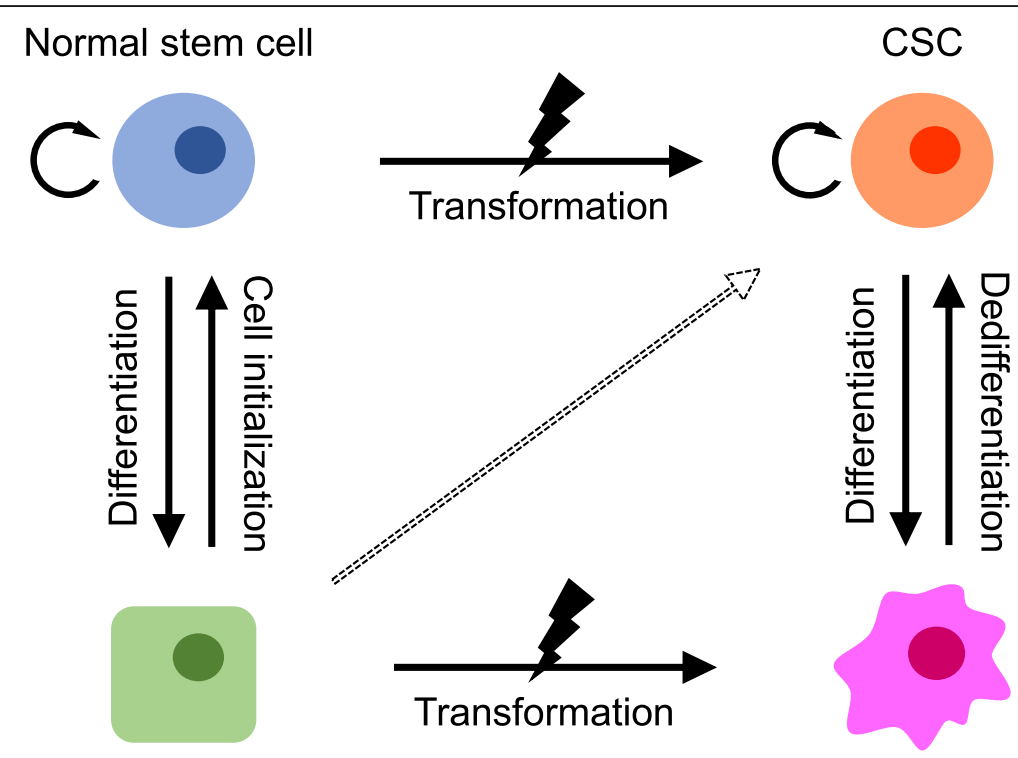

Hepatocyte/

Non-CSC

Cholangiocyte

Fig. 1 The origin of liver CSC 
in many tumors, including liver cancer, by the analysis of immunogenic, tumorigenic, or functional characteristics [23]. Currently, a number of cell surface proteins have been identified as liver CSC markers (Table 1).

\section{CD133}

CD133, which is a primitive marker of hematopoietic stem cells, neuronal stem cells, and liver stem/progenitor cells [29], was identified as a liver CSC marker in 2007 [4]. Despite the fact that CD133-positive cells represent a small population of the total number of cells in human tumor tissue [43], CD133 is clinically significant because patients with high CD133 expression have poor overall survival and higher recurrence rates compared with patients with low CD133 expression [44]. Functionally, CD133 plays a role in the maintenance of CSC properties by regulating neurotensin, interleukin (IL)-8, CXCL1, and MAPK signaling [45].

\section{CD90}

Following the identification of CD133, CD90 was identified and characterized as a marker of liver CSCs. Yang et al. found that CD90+ HCC cells, but not CD90- cells, display tumorigenic and metastatic potential $[5,6]$. Both cell line-derived CD90+ cells and liver cancer patient tissue-/blood-derived CD45- CD90+ cells generate tumor nodules in immunodeficient mice, and serial transplantation of xenografts derived from CD90+ cells produces tumor nodules in a second and subsequently third batch of immunodeficient mice [6]. These results also suggested the existence of circulating CSCs in the blood. An obvious role of CD90 in liver CSCs has not been reported.

\section{CD44}

CD44 has been used widely to characterize CSCs in combination with other cell surface markers in several solid tumors. Representatively, a CD44+ CD24-/low cell population was isolated in human breast cancer as the first CSC found in a solid tumor [46]. In terms of HCC, CD44 gives distinct cell features to the CD133+ or CD90+ CSC population. Zhu et al. indicated that CD133+ CD44+ tumor cells possess more stem cell properties, including extensive proliferation, self-renewal, and the ability to give rise to differentiated progeny, and can initiate tumor growth in NOD/SCID mice at very low cell numbers, compared with CD133+ CD44- tumor cells [47]. In addition, Yang et al. showed that CD90+ CD44+ cells demonstrate a more aggressive phenotype than CD90+ CD44- cells and form metastatic lesions in the lung of immunodeficient mice [5]. Two functions of CD44 in CSC maintenance have been reported: CD44 regulates TGF $\beta$-mediated epithelial-mesenchymal transition (EMT) [48]; and a CD44 variant regulates redox status by stabilizing $\mathrm{xCT}$ to protect CSCs against reactive oxygen species (ROS) [49].

\section{EpCAM}

EpCAM, a type 1 transmembrane glycoprotein composed of a large $\mathrm{N}$-terminal extracellular domain (EpEx)

Table 1 Identified liver CSC markers and their functions

\begin{tabular}{|c|c|c|c|}
\hline Marker & Author (year) & Function in liver CSCs & Reference \\
\hline CD133 & S. Ma [4] & Regulation of neurotensin/LL-8/CXCL1 signaling & {$[4,43]$} \\
\hline CD90 & Z. Yang [5] & Not reported & {$[5,6]$} \\
\hline CD44 & Z. Yang [6] & $\begin{array}{l}\text { Regulation of TGF-beta-mediated EMT, } \\
\text { Reduction of ROS through } \times C T \text { stabilization }\end{array}$ & {$[6,47,48]$} \\
\hline Ov6 & W. Yang [7] & Not reported & [7] \\
\hline EpCAM & T. Yamashita [8] & $\begin{array}{l}\text { Activation of Wnt signaling, } \\
\text { Induction of Wnt-regulated CSC-like } \\
\text { gene signature }\end{array}$ & {$[8,52,53]$} \\
\hline CD13 & N. Haraguchi [9] & $\begin{array}{l}\text { Cell protection from apoptosis via the ROS } \\
\text { scavenger pathway }\end{array}$ & [9] \\
\hline CD24 & T. K. Lee $[10]$ & STAT3-mediated NANOG regulation & [10] \\
\hline DLK1 & X. Xu [11] & Not reported & [11] \\
\hline$a 2 \delta 1$ & W. Zhao [12] & $\begin{array}{l}\text { Calcium influx regulation function through } \\
\mathrm{L} \text { - and } \mathrm{N} \text {-type voltage-gated calcium channels }\end{array}$ & [12] \\
\hline ICAM1 & S. Liu [13] & Not reported & [13] \\
\hline CD47 & T. K. Lee [14] & $\begin{array}{l}\text { Regulation of CSC properties by cathepsin } \\
\text { S/protease-activated receptor } 2 \text { paracrine loop }\end{array}$ & [14] \\
\hline Lgr5 & Z. J. Lei [15] & Not reported & [15] \\
\hline Keratin19 & T. Kawai [16] & Not reported & [16] \\
\hline
\end{tabular}


linked to a short C-terminal fragment (EpICD) by a single-transmembrane domain, has been recognized as one of the most representative and successful markers used in isolating liver stem cells [35]. EpCAM was identified initially as an early biomarker for HCC [50]. It was further classified as a poor prognostic subtype in combination with AFP in HCC [51]. On the basis of transcriptome analysis on a cohort of primary HCC samples, $\mathrm{EpCAM}+\mathrm{HCC}$ displayed a distinct molecular signature with features of hepatic progenitor cells, including the presence of known stem/progenitor markers, whereas EpCAM- HCC expressed genes with features of mature hepatocytes [51]. In addition, EpCAM+ HCC showed hepatic cancer stem cell-like traits, including self-renewal and differentiation, and were highly invasive and tumorigenic [8]. We further demonstrated that in comparison with $\mathrm{CD} 90+\mathrm{HCC}$, EpCAM+ HCC is highly associated with poorly differentiated morphology, high serum AFP levels, and a low incidence of distant organ metastasis [52]. This classification approach using EpCAM and CD90 might provide for a distinct clinical outcome and therapeutic approach in $\mathrm{HCC}$ patients. Mechanistically, EpCAM is one of the Wnt/ $\beta$ catenin signaling target genes in HCC [53], and the activation of $\mathrm{Wnt} / \beta$-catenin signaling enriches the EpCAM+ cell population [8]. Simultaneously, EpCAM also activates the Wnt/ $\beta$-catenin signaling by regulating intramembrane proteolysis (RIP)-mediated EpICD release [54]. Most recently, Mani et al. reported that EpCAMregulated RIP induces the activation of canonical Wnt signaling as well as the expression of a Wnt-regulated CSC-like gene signature in the presence of HBV infection [55]. These data suggest that EpCAM is strongly related to the maintenance of stem cell properties through the activation of $\mathrm{Wnt} / \beta$-catenin signaling.

\section{Other markers}

OV6, which was originally classified as a marker of hepatic progenitor cells, was also identified in a subpopulation of cells with a high ability to form tumors in vivo and with substantial resistance to standard chemotherapy [7]. OV6+ cells also exhibited strong invasive and metastatic potential both in vitro and in vivo [56]. CD13 was identified as a novel cell surface marker for CSCs by Haraguchi et al.[9]. They found that CD13+ HCC cells were CSCs enriched in a side population of cells from several HCC cell lines, predominated in the G0 phase of the cell cycle, and initiated tumor formation. Mechanistically, they found that CD13 protects cells from apoptosis via the ROS scavenger pathway. CD24, a mucinlike cell surface glycoprotein, was found to be a functional liver CSC marker that drives CSC genesis through STAT3-mediated NANOG regulation [10]. Xu et al. reported that DLK1+ HCC cells have characteristics similar to those of CSCs and showed higher levels of chemoresistance, colony formation, spheroid colony formation, and in vivo tumorigenicity than DLK1- cells [11]. Zhao et al. reported that $\alpha 2 \delta 1$ is a functional liver CSC marker identified using a monoclonal antibody against recurrent $\mathrm{HCC}$, $1 B 50-1$, which binds to the calcium channel $\alpha 2 \delta 1$ subunit. The role of $\alpha 2 \delta 1$ isoform 5 in liver CSCs is related to its regulation of calcium influx through L- and N-type voltage-gated calcium channels [12]. ICAM1, which was reported as a marker of CSCs and circulating tumor cells in humans and mice, is regulated by the stem cell transcription factor NANOG [13]. Lee et al. found that CD47 is expressed in liver CSCs, which contributes to tumor initiation, self-renewal, and metastasis, and significantly affects the clinical outcome of patients. In addition, they found that CD47+ HCC cells regulate liver CSCs through the cathepsin $\mathrm{S} /$ protease-activated receptor 2 paracrine loop [14]. Lgr5, which is also known as a marker of liver cells following damage [35], was reported to be a potential CSC marker showing high tumorigenicity and resistance to chemotherapeutic agents [15]. Most recently, keratin19, also known as CK19, was verified as a CSC marker of HCC associated with EMT and TGF $\beta /$ SMAD signaling [16]. Using a functional approach, Muramatsu et al. identified liver CSCs by visualization system of proteasome activity and ROS level. They demonstrated that HCC subpopulation with low proteasome activity/low ROS level shows liver CSC properties and tumorigenicity in vivo. They further indicated that these liver CSCs facilitate the migration of macrophages to organize their niche, and induces metastasis by the recruitment of macrophage [57].

\section{Regulation of liver CSCs \\ The liver CSC niche}

CSCs are universally believed to reside in niches, which are specialized microenvironments that regulate adult stem cell fate by providing cues in the form of both cellcell contacts and secreted factors. These niches maintain the principal properties of CSCs, preserve their phenotypic plasticity, protect them from the immune system, and facilitate their metastatic potential [58]. Although the liver CSC niche has not been elucidated, some evidence has suggested the potential regulation of liver CSCs by their niche. Fan et al. demonstrated that tumorassociated macrophage (TAM)-secreted TGF $\beta 1$ promotes CSC-like properties through EMT induction [59]. Wan et al. also reported that TAM-secreted IL- 6 promotes the expansion of CD44+ liver CSCs and tumorigenesis [60]. Moreover, non-CSC-secreted IL-17E activates the JAK/STAT3 and NF- $\mathrm{KB}$ pathways in CSCs to promote their proliferation and self-renewal in HCC [61]. Lau et al. showed that cancer-associated-fibroblast-derived HGF regulates liver CSCs via the activation of FRA1 in an Erk1/2-dependent manner [62]. Lai et al. also 
reported that lipopolysaccharide maintains the ability of CSCs to undergo tumorigenesis, migration, invasion, and develop chemoresistance through signaling of the NF- $\mathrm{KB} / \mathrm{HIF} 1 \alpha$ pathway [63]. These data suggest that the liver CSC niche could be a potential therapeutic target for liver CSCs.

\section{Molecular signaling of liver CSCs}

The $\mathrm{Wnt} / \beta$-catenin signaling pathway plays an important role in prenatal liver development, postnatal hepatic growth, adult liver homeostasis, and liver metabolism as well as liver cancer [64]. Wnt/ $\beta$-catenin activation is one of the important aberrant pathways identified in HCC. A comprehensive genome sequencing study revealed Wnt pathway-related alterations in $66 \%$ of HCCs [65]. Importantly, the activation of $\mathrm{Wnt} / \beta$-catenin signaling has been reported in CD133 + [4], EpCAM+[8], OV6 + [7], and Lgr5 + [15] CSCs. As described above, EpCAM is a direct transcriptional target of Wnt/ $\beta$-catenin signaling, and tumorigenic [53] and highly invasive EpCAM+ AFP+ $\mathrm{HCC}$ is regulated by $\mathrm{Wnt} / \beta$-catenin signaling [8].

The TGF $\beta$ family plays crucial and complex physiological roles in liver cancer, which include a multitude of distinct functions, such as maintaining stem cell homeostasis, promoting fibrosis, immune modulating, as a tumor suppressor, and paradoxically, as a tumor promoter [66]. Therefore, the role of TGF $\beta$ signaling during HCC development remains controversial. The wellknown role of TGF $\beta$ signaling as a tumor promoter in liver cancer is via EMT, in which epithelial cells acquire some stem cell characteristics through the activation of the SMAD3/4 pathway. Again, Fan et al. demonstrated that TAM-secreted TGF $\beta 1$ promotes CSC-like properties through EMT induction [59]. In addition, a few reports suggested that TGF $\beta$ can regulate the induction of liver CSCs. You et al. found that TGF $\beta 1$ regulates CD133+ CSCs by inhibiting the expression of the DNA methyltransferases DNMT1 and DNMT3 $\beta$ [67]. Conversely, the standard isoform of CD44, which is a CSC marker, regulates the TGF $\beta$-mediated mesenchymal phenotype [48]. TGF $\beta$ is also reciprocally regulated by the TLR4/NANOG oncogenic pathway in CD133+ liver CSCs [68]. IL-6/STAT3 signaling may also maintain the population of liver CSCs in collaboration with TGF $\beta$ signaling $[34,69,70]$.

The Notch signaling pathway plays a role in stem cell self-renewal and differentiation. Although the role of the Notch signaling pathway in liver cancer remains to be elucidated [71, 72], it is reportedly involved in metastasis [73] and EMT [74], which is relevant to the acquisition of a stem-like phenotype [75]. Zhu et al. reported that C8orf4 negatively regulates the self-renewal of CD13 \pm CD133 \pm liver CSCs via NOTCH2 signaling suppression [76]. The Hedgehog and HGF signaling pathways are also reportedly involved in EMT in liver cancer [77, 78]. The transcriptional coactivators TAZ and YAP, which are downstream effectors of the Hippo pathway, have oncogenic roles in human cancers. In liver cancer, Hayashi et al. demonstrated that TAZ and YAP coordinately participate in cancer progression, thereby affecting tumor growth and cancer stem-like properties [79]. ANXA3/JNK pathway has also been reported to regulate liver CSCs. Tong et al. indicated that ANXA3 promotes tumor growth and stem cell-like properties in CD133 \pm liver CSCs through the activation of JNK pathway, moreover its neutralization suppresses HCC growth and eradicates CSC subset [80].

\section{Transcription factors}

Reprogramming of cancer cells is an attractive concept for studying the biology of cancer stem cells. Normal somatic cells can be reprogrammed into induced pluripotent stem cells using four defined factors, that is, Oct4, Sox2, c-Myc, and Klf4 [81, 82]. Accumulating evidence suggests that these factors regulate the development and maintenance of liver CSCs. Oct4, which is also known as POU5F1, mediates the stemness of liver cancer via a positive feedback loop with the oncogene cJun [83]. c-Myc is a master driver of human cancers, including liver cancer, and it induces the self-renewal capacity of liver cancer cells in a p53-dependent manner [84]. Other transcription factors are also involved in the maintenance of liver CSCs. The pluripotency transcription factor NANOG is a biomarker for CSCs in HCC, and it could play an important role in the maintenance of CSC self-renewal through the IGF1R-signaling pathway [85]. Sox9 also regulates the self-renewal and tumor progression of liver CSCs through negative regulation of Numb [86].

In addition, some zinc finger transcription factors have been reported to regulate liver CSCs features. Zhu et al. demonstrated that ZIC2, which plays important roles in the early stage of organogenesis of the CNS, is highly expressed in liver CSCs and regulates the maintenance of liver CSC self-renewal through the recruitment to the NURF complex to trigger OCT4 activation [87]. SALL4, a homolog of the Drosophila homeotic gene spalt, is a zinc finger transcription factor expressed in embryonic stem cells that regulates their pluripotency and early embryonic development [88]. SALL4 is also expressed in fetal liver stem/progenitor cells, but not adult hepatocytes, and it plays a pivotal role in controlling the lineage commitment of liver stem/progenitor cells [89]. Recently, we and two other groups independently reported that SALL4 is a marker of a progenitor subtype of HCC, which is associated with poor prognosis, and a potential therapeutic target in HCC [90-92]. SALL4 represses its target 
genes, namely, phosphatase and tensin homolog and SALL1, through the epigenetic repressor NuRD complex, which contains histone deacetylases (HDACs) [93]. Indeed, high HDAC activity was detected in SALL4+ HCC cell lines, and HDAC inhibitors inhibited the proliferation of SALL4+ HCC cell lines and the expression of SALL4 gene/protein [92]. These data suggest the potential of HDAC inhibitors in the treatment of SALL4+ HCC.

\section{$\mathrm{HBV} / \mathrm{HCV}$, alcohol, and high-fat diet}

Many cancers occur in liver that has been exposed to long-lasting inflammation induced by $\mathrm{HBV} / \mathrm{HCV}$ infection, alcohol consumption, or non-alcoholic fatty liver disease [1]. Some evidence has demonstrated that these initiation factors of liver inflammation and carcinogenesis are related to the promotion of liver cancer stem properties. Arzumanyan et al. demonstrated that $\mathrm{HBx}$ promotes stemness factors and the development of HCC by activating $\beta$-catenin and epigenetic upregulation of miR-181 [94]. Ng et al. indicated that C-terminal- truncated $\mathrm{HBx}$ promotes $\mathrm{HCC}$ carcinogenesis through induction of CD133 \pm liver CSCs and its tumor-initiating capacity by regulating FXR pathway and drug metabolism [95]. HCV infection of transformed human hepatocytes leads to a significant increase in the number of spheroids, the expression of EMT and CSC markers, and tumor growth in immunodeficient mice [96]. Recently, Chen and Kumar and co-workers reported that TLR4-NANOG signaling mediates the generation of liver CSCs and tumorigenesis induced by HCV infection in combination with alcohol or a high-fat diet $[97,98]$.

\section{MicroRNAs and long noncoding RNAs}

MicroRNAs (miRNAs) are important key molecular components in cancer biology, and their dysregulation in liver cancer is related to CSC regulation. Wang and colleagues have explored the regulation of liver CSCs. They found that miR-181 is highly expressed in EpCAM+ $\mathrm{AFP}+\mathrm{HCC}$ cells as well as in embryonic livers and isolated hepatic stem cells, and it is functionally critical in the maintenance of EpCAM+ AFP $+\mathrm{HCC}$ cells by promoting HCC stemness through targeting CDX2, GATA6, and the Wnt signaling inhibitor NLK [99]. miR-155 was also identified as a molecular target that could be used to eradicate the EpCAM+ CSC population in human HCCs [100]. miR-130b is highly expressed in CD133+ CSCs and regulates CSC self-renewal and tumorigenicity via silencing TP53INP1 [101]. miR-216a/217 and miR-125 promote EMT in HCC by inhibiting PTEN/ SMAD7 and SMAD2/4, respectively [102, 103]. Most recently, Chai et al. demonstrated that miR-1246 is overexpressed in CD133 \pm liver CSCs and likely to represent a diagnostic and prognostic biomarker for HCC. Additionally, they found that overexpression of Oct4/miR-1246 signaling axis activates Wnt/ $\beta$-catenin signaling in CD133 \pm liver CSCs by suppressing AXIN2 and GSK3 $\beta$ [104].

Long noncoding RNAs (lncRNAs), which are a particular class of noncoding transcripts without evident protein coding function that are reportedly involved in the regulation of stem cell differentiation, are dysregulated in human cancers [105], and are associated with the regulation of liver CSCs. It was demonstrated that lncTCF7 is highly expressed in HCC and liver CSCs, and regulates liver CSC self-renewal and tumor propagation via the activation of Wnt signaling [106]. Yuan et al. recently indicated that lncRNA-DANCR is overexpressed in $\mathrm{HCC}$ CSCs and correlates with poor prognosis, and it mediates increasing stemness features by interacting with $\beta$-catenin in a dependent manner by blocking miRNAs [107]. Moreover, Zhu et al. reported that lnc- $\beta$ Catm, which promotes the methylation of $\beta$-catenin, also plays a role in the maintenance of CD13 \pm CD133 \pm liver CSC self-renewal via the induction of EZH2-dependent $\beta$-catenin stabilization [108].

Thus, both miRNAs and lncRNAs play an important role in regulating the properties of liver CSCs and therefore could be therapeutic targets.

\section{Epigenetic alterations}

Epigenetic alterations, including DNA methylation, histone modifications, polycomb repressive complex (PRC), and chromatin remodeling complex function, are mechanisms that contribute directly to carcinogenesis and CSC regulation. The relevance of epigenetic alterations in liver CSC regulation has been illustrated by some studies. Raggi et al. demonstrated that DNA methyltransferase DNMT1 inhibition-driven epigenetic reprogramming generates malignant properties and a pool of liver CSCs by long-lasting cell context-dependent memory effects [109]. The histone deacetylase SIRT1 was revealed to be necessary for the maintenance of self-renewal in liver CSCs and it transcriptionally regulated the SOX2 gene through DNA methylation-dependent epigenetic alteration [110]. By loss-of function assay using shorthairpin RNA and pharmacological inhibitor, Chiba et al. demonstrated that $\mathrm{EZH} 2$, a core component of $\mathrm{PRC} 2$, plays a role in the maintenance of liver CSCs, and therefore its inhibition is a promising therapeutic approach for eradication of liver CSCs [111]. Moreover, the chromatin remodeling factor CHD1L was associated with the malignance of HCC tumors and sustained an open-chromatin configuration at the promoter regions of two regulator genes of $\mathrm{HCC}$ self-renewal and differentiation [39]. 


\section{CSC-targeted therapy}

Liver cancer is an aggressive tumor with a poor prognosis. The effect of current anticancer treatments, including chemotherapy, radiotherapy, and immunotherapy, is limited to the improvement of the outcome of liver cancer patients. Accumulating evidence suggests that liver CSCs are responsible for this poor prognosis because they can survive in a dominant state after treatment due to their highly resistant nature and stem cell-like abilities (selfrenewal and differentiation). Therefore, the eradication of CSCs has been identified as a target to improve the outcome of liver cancer patients.

\section{Cell surface markers}

As described above, cell surface markers, such as CD133 and EpCAM, are highly expressed on CSC populations and regulate stemness in liver CSCs. Hence, cell surface marker-targeted therapies have been proposed to eradicate liver CSCs specifically. Anti-CD133 antibody-drug conjugates inhibited CD133+ HCC growth in vitro and in vivo [112]. An anti-CD44 antibody prevented CD90+ CD44+ CSC-mediated tumor formation both locally and systemically [5]. RNAi-based EpCAM blockade decreased the EpCAM+ CSC population and inhibited both the invasion capacity and tumorigenicity of EpCAM+ cells [8]. The CD13 inhibitor ubenimex reduced the tumorigenicity and self-renewal ability of CSCs and it suppressed CD13+ tumor growth in combination with 5FU in vivo [9]. Furthermore, CD47 blockade suppressed HCC growth and increased sensitivity to chemotherapy drugs including sorafenib $[14,113]$. These data further suggest that CSC marker-targeted therapy can provide a forceful synergic effect to existing chemotherapies.

\section{Anti-self-renewal}

Since self-renewal is an important characteristic for CSC maintenance, targeting self-renewal has also been proposed for the eradication of liver CSCs. The Wnt/ $\beta$ catenin signaling pathway is one of the most important pathways for self-renewal [53]. Inhibition of the Wnt/ $\beta$ catenin signaling pathway by anti-miR-181 inhibitors suppressed stemness gene expression and tumorigenicity of EpCAM+ HCC [99]. In addition, the small molecular agent FH535, which is a dual inhibitor of peroxisome proliferator-activated receptor and $\beta$-catenin, also showed an inhibitory effect on the proliferation of liver CSCs [114]. Lupeol, which is a phytochemical found in fruit and vegetables, suppressed the selfrenewal ability, chemoresistance, and tumorigenicity of CD133+ CSCs, and it could sensitize these cells to chemotherapeutic drugs through the PTEN-Akt-ABCG2 signaling pathway [115].

\section{Differentiation}

Inducing the differentiation of CSCs into non-CSCs to lose their self-renewal property is another possible therapeutic approach. Oncostatin M (OSM), an IL-6-related cytokine, induces the maturation of hepatocytes. We found that the OSM receptor is expressed in the majority of EpCAM+ HCC CSCs, and OSM induces the differentiation of liver CSCs and enhances their chemosensitivity to 5-FU [116]. HNF4 is a key transcription factor for hepatocyte differentiation and the maintenance of hepatic function. HNF4 $\alpha$ induces the differentiation of hepatoma cells into hepatocytes with a reduction of stemness gene expression and liver CSCs [117]. All-trans retinoic acid (ATRA), the carboxylic acid form of vitamin $\mathrm{A}$, has an important role in the regulation of cell proliferation, differentiation, and migration during development. It has been studied widely in the prevention and treatment of many types of cancer. Zhang et al. reported that ATRA induces the differentiation of EpCAM+ HCC-CSCs, resulting in improved chemosensitivity to cisplatin [118]. BMP4, which is a signaling molecule that belongs to the TGF $\beta$ superfamily, plays a role in hepatogenesis and hepatic stem cell differentiation. Zhang et al. administered BMP4 to CD133+ HCC CSCs and found that a high-dose of exogenous BMP4 promotes their differentiation, resulting in the inhibition of CSC properties [119].

\section{Chemoresistance}

Chemo- and radioresistance are well-recognized characteristics of CSCs; therefore, the elimination of such resistance of CSCs has been targeted with several treatment agents, as described above. Lupeol sensitized CSCs to chemotherapeutic drugs through the PTEN-Akt-ABCG2 signaling pathway [115]. CD47 blockade increased sensitivity to doxorubicin and sorafenib $[14,113]$. OSM and ATRA also enhanced chemosensitivity to 5-FU and cisplatin, respectively $[116,118]$. We recently reported a novel molecular target that is related to the chemoresistance of EpCAM+ liver CSCs. CHD4, a component of the NuRD complex, is recruited to UV-mediated DNA damage sites in a PARP-dependent manner [120, 121]. We found that CHD4 is highly expressed in EpCAM+ CSCs, and it plays a crucial role in the chemoresistance of these cells and the maintenance of their stemness. Furthermore, we demonstrated that targeting CHD4 using both HDAC and PARP inhibitors significantly suppressed HCC growth [122]. These results offer new mechanistic insights into the chemoresistance of HCC CSCs and suggest the clinical utility of combination therapy with HDAC/PARP inhibitors.

\section{Future directions}

As mentioned above, many aspects of the biology of liver CSCs have been revealed through great efforts and 
contributions in the past decade. However, various physiological and mechanistic questions of liver CSCs still remain to be elucidated. In addition, the CSC-based diagnosis and treatment of liver cancer both need to be improved in terms of the eradication of CSCs. Liver cancer contains heterogeneous cancer cells that have multiple biomarkers, which include cell surface markers, signaling molecules, and transcription factors. Cancer treatment has generally been selected on the basis of clinical stage; therefore, it is desirable to classify cancer in detail by a combination of various biomarkers in order to provide optimal treatment to patients. Recently, newly developed technologies have provided the ability to reveal single cell heterogeneity, which has been highlighted in cancer classification, diagnosis, and treatment [123]. Circulating tumor cells (CTCs), which are also heterogeneous cells that either originate from the primary tumor or from metastatic lesions, could be used for the detection of cancer progression in peripheral blood at an early stage and for the characterization of cancer for individualized therapy. In liver cancer, Yang et al. reported that CD45- CD90+ cells are detected in the blood of $90 \%$ of liver cancer patients [6]. Furthermore, Sun et al. found that EpCAM+ CTCs are detected in $66.67 \%$ of HCC patients by CellSearch analysis and these cells displayed stem cell-like properties. They also showed that the presence of more than 2 CTCs in $7.5 \mathrm{~mL}$ blood is an independent prognostic factor for tumor recurrence [124]. These results suggest that studying CTC heterogeneity might also be an important approach for the investigation of cancer recurrence, prognosis, and therapeutic effects.

Treatments for the eradication of CSCs require further development to be more direct, more efficient, and more effective. One of the recent approaches to target CSCs directly is nanomedicine-based therapy, in which drug delivery and release are controlled efficiently [125]. In fact, some nanomedicine-based therapies have demonstrated efficacy against liver CSCs. Epirubicinadsorbed nanodiamonds showed high efficacy in killing chemoresistant liver CSCs [126]. Poly lactic-co-glycolic acid-encapsulated disulfiram strongly inhibited liver CSCs, in vivo HCC growth, and metastasis in combination with copper [127].

CSC-targeted immunotherapies are also an interesting treatment strategy for eliminating liver CSCs. Among them, chimeric antigen receptor $\mathrm{T}$ cell $(\mathrm{CAR}-\mathrm{T})$ treatment has recently been highlighted and investigated for its clinical use in many tumors, mainly in hematopoietic tumors [128, 129]. In terms of HCC, Gao et al. developed a GPC3-targeted CAR and investigated its efficacy in vivo. They found that GPC3-targeted CAR-T suppresses HCC growth [130]. Since CSCs express single or multiple specific cell surface markers, CSC antigen-targeted CAR-T could be used for the direct eradication of CSCs. For example,
EpCAM-specific CAR-expressing human peripheral blood lymphocytes inhibited tumor growth in an EpCAM+ prostate cancer metastasis mouse model [131]. In sum, although liver CSC-targeted CAR-T therapy has not been reported, it can be considered a promising approach.

While these newly developed therapeutic approaches are exceedingly attractive, their adverse effects on normal stem cells should be carefully considered because CSCs share similar features with normal stem cells, including activated markers and signaling pathways. The eradication of normal stem cells as well as CSCs would prove fatal to liver cancer patients with chronic liver disease; therefore, the future challenge is to identify specific CSC markers and develop a specific treatment for liver CSCs.

\section{Conclusions}

Since the presence of CSCs has been recognized as one of the risk factors for a high recurrence rate and chemoresistance of liver cancers, the novel therapeutic approaches are clearly required to eradicate liver CSCs. On the basis of the current understanding of the biology of liver CSCs presented here, further efforts should be made for the application of the CSCs biology in the clinical setting to eradicate liver cancers.

\begin{abstract}
Abbreviations
ATRA: All-trans retinoic acid; CAR-T: Chimeric antigen receptor T cell; CSC: Cancer stem cell; CTC: Circulating tumor cell; EMT: Epithelial-mesenchymal transition; HBV: Hepatitis B virus; HCC: Hepatocellular carcinoma; HCV: Hepatitis C virus; HDAC: Histone deacetylase; ICC: Intrahepatic cholangiocarcinoma;

IL: Interleukin; IncRNA: Long noncoding RNA; miRNA: microRNA; OSM: Oncostatin M; PRC: Polycomb repressive complex; RIP: Regulated intramembrane proteolysis; ROS: Reactive oxygen species; TAM: Tumor-associated macrophage
\end{abstract}

\section{Acknowledgements}

We apologize to those authors whose original works were not cited due to space limitations.

\section{Funding}

This work was supported by Kanazawa University CHOZEN Project.

Availability of data and materials

Not applicable.

Authors' contributions

$\mathrm{KN}$ was a major contributor in writing the manuscript. All authors read and approved the final manuscript.

Competing interests

The authors declare that they have no competing interests.

Consent for publication

Not applicable.

Ethics approval and consent to participate

Not applicable.

\section{Author details}

'Lineberger Comprehensive Cancer Center, The University of North Carolina at Chapel Hill, Marsico Hall 5229 M, 125 Mason Farm Rd, 27599 Chapel Hill, NC, USA. ${ }^{2}$ Department of Gastroenterology, Kanazawa University Graduate School of Medical Science, 13-1 Takara-Machi, 920-8641 Kanazawa, Ishikawa, Japan. 
Received: 14 October 2016 Accepted: 19 December 2016 Published online: 30 January 2017

\section{References}

1. Jemal A, Bray F, Center MM, Ferlay J, Ward E, Forman D. Global cancer statistics. CA Cancer J Clin. 2011;61:69-90.

2. Simard EP, Ward EM, Siegel R, Jemal A. Cancers with increasing incidence trends in the United States: 1999 through 2008. CA Cancer J Clin. 2012;62: 118-28.

3. Visvader JE, Lindeman GJ. Cancer stem cells in solid tumours: accumulating evidence and unresolved questions. Nat Rev Cancer. 2008;8:755-68.

4. Ma S, Chan KW, Hu L, Lee TK, Wo JY, Ng IO, Zheng BJ, Guan XY. Identification and characterization of tumorigenic liver cancer stem/ progenitor cells. Gastroenterology. 2007;132:2542-56.

5. Yang ZF, Ho DW, Ng MN, Lau CK, Yu WC, Ngai P, Chu PW, Lam CT, Poon RT, Fan ST. Significance of CD90+ cancer stem cells in human liver cancer. Cancer Cell. 2008:13:153-66.

6. Yang ZF, Ngai P, Ho DW, Yu WC, Ng MN, Lau CK, Li ML, Tam KH, Lam CT, Poon RT, Fan ST. Identification of local and circulating cancer stem cells in human liver cancer. Hepatology. 2008;47:919-28.

7. Yang W, Yan HX, Chen L, Liu Q, He YQ, Yu LX, Zhang SH, Huang DD, Tang L, Kong $X N$, et al. Wnt/beta-catenin signaling contributes to activation of normal and tumorigenic liver progenitor cells. Cancer Res. 2008;68:4287-95.

8. Yamashita T, Ji J, Budhu A, Forgues M, Yang W, Wang HY, Jia H, Ye Q, Qin LX, Wauthier E, et al. EpCAM-positive hepatocellular carcinoma cells are tumorinitiating cells with stem/progenitor cell features. Gastroenterology. 2009;136: 1012-24.

9. Haraguchi N, Ishii H, Mimori K, Tanaka F, Ohkuma M, Kim HM, Akita H, Takiuchi D, Hatano H, Nagano H, et al. CD13 is a therapeutic target in human liver cancer stem cells. J Clin Invest. 2010;120:3326-39.

10. Lee TK, Castilho A, Cheung VC, Tang KH, Ma S, Ng IO. CD24 (+) liver tumorinitiating cells drive self-renewal and tumor initiation through STAT3mediated NANOG regulation. Cell Stem Cell. 2011;9:50-63.

11. Xu X, Liu RF, Zhang X, Huang LY, Chen F, Fei QL, Han ZG. DLK1 as a potential target against cancer stem/progenitor cells of hepatocellular carcinoma. Mol Cancer Ther. 2012;11:629-38.

12. Zhao W, Wang L, Han H, Jin K, Lin N, Guo T, Chen Y, Cheng H, Lu F, Fang W, et al. 1B50-1, a mAb raised against recurrent tumor cells, targets liver tumorinitiating cells by binding to the calcium channel a2 $\delta 1$ subunit. Cancer Cell. 2013;23:541-56.

13. Liu S, Li N, Yu X, Xiao X, Cheng K, Hu J, Wang J, Zhang D, Cheng S. Expression of intercellular adhesion molecule 1 by hepatocellular carcinoma stem cells and circulating tumor cells. Gastroenterology. 2013;144(10311041):e1010.

14. Lee TK, Cheung VC, Lu P, Lau EY, Ma S, Tang KH, Tong M, Lo J, Ng IO. Blockade of CD47-mediated cathepsin S/protease-activated receptor 2 signaling provides a therapeutic target for hepatocellular carcinoma. Hepatology. 2014;60:179-91.

15. Lei ZJ, Wang J, Xiao HL, Guo Y, Wang T, Li Q, Liu L, Luo X, Fan LL, Lin L, et al. Lysine-specific demethylase 1 promotes the stemness and chemoresistance of Lgr5 (+) liver cancer initiating cells by suppressing negative regulators of $\beta$-catenin signaling. Oncogene. 2015:34:3188-98.

16. Kawai T, Yasuchika K, Ishii T, Katayama H, Yoshitoshi EY, Ogiso S, Kita S, Yasuda K, Fukumitsu K, Mizumoto M, et al. Keratin 19, a Cancer Stem Cell Marker in Human Hepatocellular Carcinoma. Clin Cancer Res. 2015;21:3081-91.

17. Nowell PC. The clonal evolution of tumor cell populations. Science. 1976; 194:23-8.

18. Fidler IJ, Gersten DM, Hart IR. The biology of cancer invasion and metastasis. Adv Cancer Res. 1978;28:149-250.

19. Heppner GH. Tumor heterogeneity. Cancer Res. 1984;44:2259-65.

20. Baylin SB, Jones PA. A decade of exploring the cancer epigenome biological and translational implications. Nat Rev Cancer. 2011;11:726-34.

21. Bissell MJ, Hines WC. Why don't we get more cancer? A proposed role of the microenvironment in restraining cancer progression. Nat Med. 2011;17 320-9.

22. Shackleton M, Quintana E, Fearon ER, Morrison SJ. Heterogeneity in cancer: cancer stem cells versus clonal evolution. Cell. 2009;138:822-9.

23. Magee JA, Piskounova E, Morrison SJ. Cancer stem cells: impact, heterogeneity, and uncertainty. Cancer Cell. 2012;21:283-96.

24. Hamburger AW, Salmon SE. Primary bioassay of human tumor stem cells. Science. 1977;197:461-3.
25. Dang HT, Budhu A, Wang XW. The origin of cancer stem cells. J Hepatol. 2014;60:1304-5.

26. Cheng Z, Li X, Ding J. Characteristics of liver cancer stem cells and clinical correlations. Cancer Lett. 2016;379:230-8.

27. Schmelzer E, Zhang L, Bruce A, Wauthier E, Ludlow J, Yao HL, Moss N, Melhem A, McClelland R, Turner W, et al. Human hepatic stem cells from fetal and postnatal donors. J Exp Med. 2007;204:1973-87.

28. Huch M, Dorrell C, Boj SF, van Es JH, Li VS, van de Wetering M, Sato T, Hamer K, Sasaki N, Finegold MJ, et al. In vitro expansion of single Lgr5+ liver stem cells induced by Wnt-driven regeneration. Nature. 2013;494:247-50.

29. Rountree CB, Barsky L, Ge S, Zhu J, Senadheera S, Crooks GM. A CD133expressing murine liver oval cell population with bilineage potential. Stem Cells. 2007;25:2419-29.

30. Qiu Q, Hernandez JC, Dean AM, Rao PH, Darlington GJ. CD24-positive cells from normal adult mouse liver are hepatocyte progenitor cells. Stem Cells Dev. 2011;20:2177-88.

31. Yamashita T, Wang XW. Cancer stem cells in the development of liver cancer. J Clin Invest. 2013;123:1911-8.

32. He G, Dhar D, Nakagawa H, Font-Burgada J, Ogata H, Jiang Y, Shalapour S, Seki E, Yost SE, Jepsen $\mathrm{K}$, et al. Identification of liver cancer progenitors whose malignant progression depends on autocrine IL-6 signaling. Cell. 2013;155:384-96.

33. Wu K, Ding J, Chen C, Sun W, Ning BF, Wen W, Huang L, Han T, Yang W, Wang $C$, et al. Hepatic transforming growth factor beta gives rise to tumorinitiating cells and promotes liver cancer development. Hepatology. 2012; 56:2255-67.

34. Tang Y, Kitisin K, Jogunoori W, Li C, Deng CX, Mueller SC, Ressom HW, Rashid A, He AR, Mendelson JS, et al. Progenitor/stem cells give rise to liver cancer due to aberrant TGF-beta and IL-6 signaling. Proc Natl Acad Sci U S A. 2008;105:2445-50.

35. Huch M, Dollé L. The plastic cellular states of liver cells: Are EpCAM and Lgr5 fit for purpose? Hepatology. 2016;64:652-62.

36. Holczbauer A, Factor VM, Andersen JB, Marquardt JU, Kleiner DE, Raggi C, Kitade M, Seo D, Akita H, Durkin ME, Thorgeirsson SS. Modeling pathogenesis of primary liver cancer in lineage-specific mouse cell types. Gastroenterology. 2013;145:221-31.

37. Chaffer CL, Brueckmann I, Scheel C, Kaestli AJ, Wiggins PA, Rodrigues LO, Brooks M, Reinhardt F, Su Y, Polyak K, et al. Normal and neoplastic nonstem cells can spontaneously convert to a stem-like state. Proc Natl Acad Sci U S A. 2011;108:7950-5.

38. Mani SA, Guo W, Liao MJ, Eaton EN, Ayyanan A, Zhou AY, Brooks M, Reinhard F, Zhang CC, Shipitsin M, et al. The epithelial-mesenchymal transition generates cells with properties of stem cells. Cell. 2008;133:704-15.

39. Liu M, Chen L, Ma NF, Chow RK, Li Y, Song Y, Chan TH, Fang S, Yang X, Xi S, et al. CHD1L promotes lineage reversion of hepatocellular carcinoma through opening chromatin for key developmental transcription factors. Hepatology. 2016;63:1544-59.

40. Sekiya S, Suzuki A. Intrahepatic cholangiocarcinoma can arise from Notchmediated conversion of hepatocytes. J Clin Invest. 2012;122:3914-8.

41. Fan B, Malato Y, Calvisi DF, Naqvi S, Razumilava N, Ribback S, Gores GJ, Dombrowski F, Evert M, Chen X, Willenbring H. Cholangiocarcinomas can originate from hepatocytes in mice. J Clin Invest. 2012;122:2911-5.

42. Lapidot T, Sirard C, Vormoor J, Murdoch B, Hoang T, Caceres-Cortes J, Minden M, Paterson B, Caligiuri MA, Dick JE. A cell initiating human acute myeloid leukaemia after transplantation into SCID mice. Nature. 1994;367:645-8.

43. Yin S, Li J, Hu C, Chen X, Yao M, Yan M, Jiang G, Ge C, Xie H, Wan D, et al. CD133 positive hepatocellular carcinoma cells possess high capacity for tumorigenicity. Int J Cancer. 2007;120:1444-50.

44. Song W, Li H, Tao K, Li R, Song Z, Zhao Q, Zhang F, Dou K. Expression and clinical significance of the stem cell marker CD133 in hepatocellular carcinoma. Int J Clin Pract. 2008:62:1212-8.

45. Tang KH, Ma S, Lee TK, Chan YP, Kwan PS, Tong CM, Ng IO, Man K, To KF, Lai PB, et al. CD133 (+) liver tumor-initiating cells promote tumor angiogenesis, growth, and self-renewal through neurotensin/interleukin-8/ CXCL1 signaling. Hepatology. 2012;55:807-20.

46. Al-Hajj M, Wicha MS, Benito-Hernandez A, Morrison SJ, Clarke MF. Prospective identification of tumorigenic breast cancer cells. Proc Natl Acad Sci U S A. 2003;100:3983-8.

47. Zhu Z, Hao X, Yan M, Yao M, Ge C, Gu J, Li J. Cancer stem/progenitor cells are highly enriched in CD133 + CD44+ population in hepatocellular carcinoma. Int J Cancer. 2010;126:2067-78. 
48. Mima K, Okabe H, Ishimoto T, Hayashi H, Nakagawa S, Kuroki H, Watanabe M, Beppu T, Tamada M, Nagano O, et al. CD44s regulates the TGF- $\beta$-mediated mesenchymal phenotype and is associated with poor prognosis in patients with hepatocellular carcinoma. Cancer Res. 2012;72:3414-23.

49. Ishimoto T, Nagano O, Yae T, Tamada M, Motohara T, Oshima H, Oshima M, Ikeda T, Asaba R, Yagi H, et al. CD44 variant regulates redox status in cancer cells by stabilizing the $\mathrm{xCT}$ subunit of system $\mathrm{xc}(-)$ and thereby promotes tumor growth. Cancer Cell. 2011;19:387-400.

50. Kim JW, Ye Q, Forgues M, Chen Y, Budhu A, Sime J, Hofseth LJ, Kaul R, Wang XW. Cancer-associated molecular signature in the tissue samples of patients with cirrhosis. Hepatology. 2004;39:518-27.

51. Yamashita T, Forgues M, Wang W, Kim JW, Ye Q, Jia H, Budhu A, Zanetti KA, Chen Y, Qin LX, et al. EpCAM and alpha-fetoprotein expression defines novel prognostic subtypes of hepatocellular carcinoma. Cancer Res. 2008;68:1451-61.

52. Yamashita T, Honda M, Nakamoto Y, Baba M, Nio K, Hara Y, Zeng SS, Hayashi T, Kondo M, Takatori $\mathrm{H}$, et al. Discrete nature of EpCAM+ and CD90+ cancer stem cells in human hepatocellular carcinoma. Hepatology. 2013;57: 1484-97.

53. Yamashita T, Budhu A, Forgues M, Wang XW. Activation of hepatic stem cell marker EpCAM by Wnt-beta-catenin signaling in hepatocellular carcinoma. Cancer Res. 2007;67:10831-9.

54. Maetzel D, Denzel S, Mack B, Canis M, Went P, Benk M, Kieu C, Papior P, Baeuerle PA, Munz M, Gires O. Nuclear signalling by tumour-associated antigen EpCAM. Nat Cell Biol. 2009;11:162-71.

55. Mani SK, Zhang H, Diab A, Pascuzzi PE, Lefrançois L, Fares N, Bancel B, Merle P, Andrisani O. EpCAM-regulated intramembrane proteolysis induces a cancer stem cell-like gene signature in hepatitis B virus-infected hepatocytes. J Hepatol. 2016.

56. Yang W, Wang C, Lin Y, Liu Q, Yu LX, Tang L, Yan HX, Fu J, Chen Y, Zhang HL, et al. OV6 ${ }^{+}$tumor-initiating cells contribute to tumor progression and invasion in human hepatocellular carcinoma. J Hepatol. 2012;57:613-20.

57. Muramatsu S, Tanaka S, Mogushi K, Adikrisna R, Aihara A, Ban D, Ochiai T, Irie T, Kudo A, Nakamura N, et al. Visualization of stem cell features in human hepatocellular carcinoma reveals in vivo significance of tumor-host interaction and clinical course. Hepatology. 2013;58:218-28.

58. Plaks V, Kong N, Werb Z. The cancer stem cell niche: how essential is the niche in regulating stemness of tumor cells? Cell Stem Cell. 2015;16:225-38.

59. Fan $Q M$, Jing YY, Yu GF, Kou XR, Ye F, Gao L, Li R, Zhao QD, Yang Y, Lu ZH, Wei LX. Tumor-associated macrophages promote cancer stem cell-like properties via transforming growth factor-beta1-induced epithelial-mesenchymal transition in hepatocellular carcinoma. Cancer Lett. 2014;352:160-8.

60. Wan S, Zhao E, Kryczek I, Vatan L, Sadovskaya A, Ludema G, Simeone DM, Zou W, Welling TH. Tumor-associated macrophages produce interleukin 6 and signal via STAT3 to promote expansion of human hepatocellular carcinoma stem cells. Gastroenterology. 2014;147:1393-404.

61. Luo Y, Yang Z, Su L, Shan J, Xu H, Xu Y, Liu L, Zhu W, Chen X, Liu C, et al. Non-CSCs nourish CSCs through interleukin-17E-mediated activation of NF-kB and JAKSSTAT3 signaling in human hepatocellular carcinoma. Cancer Lett. 2016;375:390-9.

62. Lau EY, Lo J, Cheng BY, Ma MK, Lee JM, Ng JK, Chai S, Lin CH, Tsang SY, Ma S, et al. Cancer-Associated Fibroblasts Regulate Tumor-Initiating Cell Plasticity in Hepatocellular Carcinoma through c-Met/FRA1/HEY1 Signaling. Cell Rep. 2016; 15:1175-89.

63. Lai FB, Liu WT, Jing YY, Yu GF, Han ZP, Yang X, Zeng JX, Zhang HJ, Shi RY, Li XY, et al. Lipopolysaccharide supports maintaining the stemness of CD133 (+) hepatoma cells through activation of the NF-KB/HIF-1a pathway. Cancer Lett. 2016:378:131-41.

64. Monga SP. Role of Wnt/ $\beta$-catenin signaling in liver metabolism and cancer. Int J Biochem Cell Biol. 2011:43:1021-9.

65. Totoki Y, Tatsuno K, Covington KR, Ueda H, Creighton CJ, Kato M, Tsuji S, Donehower LA, Slagle BL, Nakamura H, et al. Trans-ancestry mutational landscape of hepatocellular carcinoma genomes. Nat Genet. 2014;46: 1267-73.

66. Katz LH, Likhter M, Jogunoori W, Belkin M, Ohshiro K, Mishra L. TGF- $\beta$ signaling in liver and gastrointestinal cancers. Cancer Lett. 2016;379:166-72.

67. You H, Ding W, Rountree CB. Epigenetic regulation of cancer stem cell marker CD133 by transforming growth factor-beta. Hepatology. 2010;51: 1635-44.

68. Chen CL, Tsukamoto H, Liu JC, Kashiwabara C, Feldman D, Sher L, Dooley S, French SW, Mishra L, Petrovic $L$, et al. Reciprocal regulation by TLR4 and TGF- $\beta$ in tumor-initiating stem-like cells. J Clin Invest. 2013;123:2832-49.
69. Mishra L, Banker T, Murray J, Byers S, Thenappan A, He AR, Shetty K, Johnson L, Reddy EP. Liver stem cells and hepatocellular carcinoma. Hepatology. 2009:49:318-29.

70. Lin L, Amin R, Gallicano Gl, Glasgow E, Jogunoori W, Jessup JM, Zasloff M, Marshall JL, Shetty K, Johnson L, et al. The STAT3 inhibitor NSC 74859 is effective in hepatocellular cancers with disrupted TGF-beta signaling. Oncogene. 2009;28:961-72.

71. Viatour P, Ehmer U, Saddic LA, Dorrell C, Andersen JB, Lin C, Zmoos AF, Mazur PK, Schaffer BE, Ostermeier A, et al. Notch signaling inhibits hepatocellular carcinoma following inactivation of the RB pathway. J Exp Med. 2011;208:1963-76.

72. Villanueva A, Alsinet C, Yanger K, Hoshida Y, Zong Y, Toffanin S, RodriguezCarunchio L, Solé M, Thung S, Stanger BZ, Llovet JM. Notch signaling is activated in human hepatocellular carcinoma and induces tumor formation in mice. Gastroenterology. 2012;143(1660-1669):e1667.

73. Wang XQ, Zhang W, Lui EL, Zhu Y, Lu P, Yu X, Sun J, Yang S, Poon RT, Fan ST. Notch1-Snail1-E-cadherin pathway in metastatic hepatocellular carcinoma. Int J Cancer. 2012;131:E163-172.

74. Xiao S, Chang RM, Yang MY, Lei X, Liu X, Gao WB, Xiao JL, Yang LY. Actinlike $6 \mathrm{~A}$ predicts poor prognosis of hepatocellular carcinoma and promotes metastasis and epithelial-mesenchymal transition. Hepatology. 2016;63: 1256-71.

75. Sato R, Semba T, Saya H, Arima Y. Concise Review: Stem Cells and EpithelialMesenchymal Transition in Cancer: Biological Implications and Therapeutic Targets. Stem Cells. 2016;34:1997-2007.

76. Zhu P, Wang Y, Du Y, He L, Huang G, Zhang G, Yan X, Fan Z. C8orf4 negatively regulates self-renewal of liver cancer stem cells via suppression of NOTCH2 signalling. Nat Commun. 2015;6:7122.

77. Steinway SN, Zañudo JG, Ding W, Rountree CB, Feith DJ, Loughran TP, Albert R. Network modeling of TGF $\beta$ signaling in hepatocellular carcinoma epithelial-to-mesenchymal transition reveals joint sonic hedgehog and Wnt pathway activation. Cancer Res. 2014;74:5963-77.

78. Ding W, You H, Dang H, LeBlanc F, Galicia V, Lu SC, Stiles B, Rountree CB. Epithelial-to-mesenchymal transition of murine liver tumor cells promotes invasion. Hepatology. 2010;52:945-53.

79. Hayashi H, Higashi T, Yokoyama N, Kaida T, Sakamoto K, Fukushima Y, Ishimoto T, Kuroki H, Nitta H, Hashimoto D, et al. An Imbalance in TAZ and YAP Expression in Hepatocellular Carcinoma Confers Cancer Stem Cell-like Behaviors Contributing to Disease Progression. Cancer Res. 2015;75:4985-97.

80. Tong M, Fung TM, Luk ST, Ng KY, Lee TK, Lin CH, Yam JW, Chan KW, Ng F, Zheng BJ, et al. ANXA3/JNK Signaling Promotes Self-Renewal and Tumor Growth, and Its Blockade Provides a Therapeutic Target for Hepatocellular Carcinoma. Stem Cell Rep. 2015;5:45-59.

81. Takahashi K, Yamanaka S. Induction of pluripotent stem cells from mouse embryonic and adult fibroblast cultures by defined factors. Cell. 2006;126:663-76.

82. Takahashi K, Tanabe K, Ohnuki M, Narita M, Ichisaka T, Tomoda K, Yamanaka S. Induction of pluripotent stem cells from adult human fibroblasts by defined factors. Cell. 2007;131:861-72.

83. Kuo KK, Lee KT, Chen KK, Yang YH, Lin YC, Tsai MH, Wuputra K, Lee YL, Ku CC, Miyoshi H, et al. Positive Feedback Loop of OCT4 and c-JUN Expedites Cancer Stemness in Liver Cancer. Stem Cells. 2016.

84. Akita H, Marquardt JU, Durkin ME, Kitade M, Seo D, Conner EA, Andersen JB, Factor VM, Thorgeirsson SS. MYC activates stem-like cell potential in hepatocarcinoma by a p53-dependent mechanism. Cancer Res. 2014;74: 5903-13.

85. Shan J, Shen J, Liu L, Xia F, Xu C, Duan G, Xu Y, Ma Q, Yang Z, Zhang Q, et al. Nanog regulates self-renewal of cancer stem cells through the insulinlike growth factor pathway in human hepatocellular carcinoma. Hepatology. 2012;56:1004-14.

86. Liu C, Liu L, Chen X, Cheng J, Zhang H, Shen J, Shan J, Xu Y, Yang Z, Lai M, Qian C. Sox9 regulates self-renewal and tumorigenicity by promoting symmetrical cell division of cancer stem cells in hepatocellular carcinoma. Hepatology. 2016;64:117-29.

87. Zhu P, Wang Y, He L, Huang G, Du Y, Zhang G, Yan X, Xia P, Ye B, Wang S, et al. ZIC2-dependent OCT4 activation drives self-renewal of human liver cancer stem cells. J Clin Invest. 2015;125:3795-808.

88. Zhang J, Tam WL, Tong GQ, Wu Q, Chan HY, Soh BS, Lou Y, Yang J, Ma Y, Chai $L$, et al. Sall4 modulates embryonic stem cell pluripotency and early embryonic development by the transcriptional regulation of Pou5f1. Nat Cell Biol. 2006:8:1114-23. 
89. Oikawa T, Kamiya A, Kakinuma S, Zeniya M, Nishinakamura R, Tajiri H, Nakauchi H. Sall4 regulates cell fate decision in fetal hepatic stem/ progenitor cells. Gastroenterology. 2009;136:1000-11.

90. Yong KJ, Gao C, Lim JS, Yan B, Yang H, Dimitrov T, Kawasaki A, Ong CW, Wong KF, Lee $\mathrm{S}$, et al. Oncofetal gene SALL4 in aggressive hepatocellular carcinoma. N Engl J Med. 2013;368:2266-76.

91. Oikawa T, Kamiya A, Zeniya M, Chikada H, Hyuck AD, Yamazaki Y, Wauthier E, Tajiri H, Miller LD, Wang XW, et al. Sal-like protein 4 (SALL4), a stem cell biomarker in liver cancers. Hepatology. 2013;57:1469-83.

92. Zeng SS, Yamashita T, Kondo M, Nio K, Hayashi T, Hara Y, Nomura Y, Yoshida M, Oishi N, Ikeda H, et al. The transcription factor SALL4 regulates stemness of EpCAM-positive hepatocellular carcinoma. J Hepatol. 2014;60:127-34.

93. Lu J, Jeong HW, Jeong H, Kong N, Yang Y, Carroll J, Luo HR, Silberstein LE, Yupoma CL. Stem cell factor SALL4 represses the transcriptions of PTEN and SALL1 through an epigenetic repressor complex. PLoS One. 2009;4:e5577.

94. Arzumanyan A, Friedman T, Ng IO, Clayton MM, Lian Z, Feitelson MA. Does the hepatitis B antigen HBx promote the appearance of liver cancer stem cells? Cancer Res. 2011;71:3701-8.

95. Ng KY, Chai S, Tong M, Guan XY, Lin CH, Ching YP, Xie D, Cheng AS, Ma S. $C$-terminal truncated hepatitis $B$ virus $X$ protein promotes hepatocellular carcinogenesis through induction of cancer and stem cell-like properties. Oncotarget. 2016;7:24005-17.

96. Kwon YC, Bose SK, Steele R, Meyer K, Di Bisceglie AM, Ray RB, Ray R. Promotion of Cancer Stem-Like Cell Properties in Hepatitis C Virus-Infected Hepatocytes. J Virol. 2015;89:11549-56.

97. Chen CL, Uthaya Kumar DB, Punj V, Xu J, Sher L, Tahara SM, Hess S, Machida K. NANOG Metabolically Reprograms Tumor-Initiating Stem-like Cells through Tumorigenic Changes in Oxidative Phosphorylation and Fatty Acid Metabolism. Cell Metab. 2016;23:206-19.

98. Uthaya Kumar DB, Chen CL, Liu JC, Feldman DE, Sher LS, French S, DiNorcia J, French SW, Naini BV, Junrungsee S, et al. TLR4 Signaling via NANOG Cooperates With STAT3 to Activate Twist1 and Promote Formation of TumorInitiating Stem-Like Cells in Livers of Mice. Gastroenterology. 2016;150:707-19.

99. Ji J, Yamashita T, Budhu A, Forgues M, Jia HL, Li C, Deng C, Wauthier E, Reid LM, Ye QH, et al. Identification of microRNA-181 by genome-wide screening as a critical player in EpCAM-positive hepatic cancer stem cells. Hepatology. 2009;50:472-80.

100. Ji J, Zheng X, Forgues M, Yamashita T, Wauthier EL, Reid LM, Wen X, Song Y, Wei JS, Khan J, et al. Identification of microRNAs specific for epithelial cell adhesion molecule-positive tumor cells in hepatocellular carcinoma. Hepatology. 2015;62:829-40.

101. Ma S, Tang KH, Chan YP, Lee TK, Kwan PS, Castilho A, Ng I, Man K, Wong N, To KF, et al. miR-130b Promotes CD133 (+) liver tumor-initiating cell growth and self-renewal via tumor protein 53-induced nuclear protein 1. Cell Stem Cell. 2010;7:694-707.

102. Xia H, Ooi LL, Hui KM. MicroRNA-216a/217-induced epithelial-mesenchymal transition targets PTEN and SMAD7 to promote drug resistance and recurrence of liver cancer. Hepatology. 2013;58:629-41.

103. Zhou JN, Zeng Q, Wang HY, Zhang B, Li ST, Nan X, Cao N, Fu CJ, Yan XL, Jia $Y L$, et al. MicroRNA-125b attenuates epithelial-mesenchymal transitions and targets stem-like liver cancer cells through small mothers against decapentaplegic 2 and 4. Hepatology. 2015;62:801-15.

104. Chai S, Ng K-Y, Tong M, Lau EY, Lee TK, Chan KW, Yuan Y-F, Cheung T-T, Cheung S-T, Wang X-Q, Wong N, Lo C-M, Man K, Guan X-Y, Ma S. Octamer 4/microRNA-1246 signaling axis drives Wnt/B-catenin activation in liver cancer stem cells. Hepatology. 2016;64:2062-76. doi:10.1002/hep.28821.

105. Gutschner T, Diederichs S. The hallmarks of cancer: a long non-coding RNA point of view. RNA Biol. 2012;9:703-19.

106. Wang Y, He L, Du Y, Zhu P, Huang G, Luo J, Yan X, Ye B, Li C, Xia P, et al. The long noncoding RNA IncTCF7 promotes self-renewal of human liver cancer stem cells through activation of Wnt signaling. Cell Stem Cell. 2015;16:413-25.

107. Yuan SX, Wang J, Yang F, Tao QF, Zhang J, Wang LL, Yang Y, Liu H, Wang ZG, Xu QG, et al. Long noncoding RNA DANCR increases stemness features of hepatocellular carcinoma by derepression of CTNNB1. Hepatology. 2016;63:499-511.

108. Zhu P, Wang Y, Huang G, Ye B, Liu B, Wu J, Du Y, He L. Fan Z: Inc-B-Catm elicits EZH2-dependent $\beta$-catenin stabilization and sustains liver CSC selfrenewal. Nat Struct Mol Biol. 2016;23:631-9.

109. Raggi C, Factor VM, Seo D, Holczbauer A, Gillen MC, Marquardt JU, Andersen JB, Durkin $M$, Thorgeirsson SS. Epigenetic reprogramming modulates malignant properties of human liver cancer. Hepatology. 2014;59:2251-62.
110. Liu L, Liu C, Zhang Q, Shen J, Zhang H, Shan J, Duan G, Guo D, Chen X, Cheng J, et al. SIRT1-mediated transcriptional regulation of SOX2 is important for self-renewal of liver cancer stem cells. Hepatology. 2016;64: 814-27.

111. Chiba T, Suzuki E, Negishi M, Saraya A, Miyagi S, Konuma T, Tanaka S, Tada M, Kanai F, Imazeki F, et al. 3-Deazaneplanocin A is a promising therapeutic agent for the eradication of tumor-initiating hepatocellular carcinoma cells. Int J Cancer. 2012;130:2557-67.

112. Smith LM, Nesterova A, Ryan MC, Duniho S, Jonas M, Anderson M, Zabinski RF, Sutherland MK, Gerber HP, Van Orden KL, et al. CD133/prominin-1 is a potential therapeutic target for antibody-drug conjugates in hepatocellular and gastric cancers. Br J Cancer. 2008:99:100-9.

113. Lo J, Lau EY, Ching RH, Cheng BY, Ma MK, Ng IO, Lee TK. Nuclear factor kappa B-mediated CD47 up-regulation promotes sorafenib resistance and its blockade synergizes the effect of sorafenib in hepatocellular carcinoma in mice. Hepatology. 2015;62:534-45.

114. Gedaly R, Galuppo R, Daily MF, Shah M, Maynard E, Chen C, Zhang X, Esser KA, Cohen DA, Evers BM, et al. Targeting the Wnt/ $\beta$-catenin signaling pathway in liver cancer stem cells and hepatocellular carcinoma cell lines with FH535. PLoS One. 2014;9:e99272.

115. Lee TK, Castilho A, Cheung VC, Tang KH, Ma S, Ng IO. Lupeol targets liver tumor-initiating cells through phosphatase and tensin homolog modulation. Hepatology. 2011;53:160-70.

116. Yamashita T, Honda M, Nio K, Nakamoto Y, Takamura H, Tani T, Zen Y, Kaneko S. Oncostatin $\mathrm{m}$ renders epithelial cell adhesion molecule-positive liver cancer stem cells sensitive to 5-Fluorouracil by inducing hepatocytic differentiation. Cancer Res. 2010;70:4687-97.

117. Yin C, Lin Y, Zhang X, Chen YX, Zeng X, Yue HY, Hou JL, Deng X, Zhang JP, Han ZG, Xie WF. Differentiation therapy of hepatocellular carcinoma in mice with recombinant adenovirus carrying hepatocyte nuclear factor-4alpha gene. Hepatology. 2008;48:1528-39.

118. Zhang Y, Guan DX, Shi J, Gao H, Li JJ, Zhao JS, Qiu L, Liu J, Li N, Guo WX, et al. All-trans retinoic acid potentiates the chemotherapeutic effect of cisplatin by inducing differentiation of tumor initiating cells in liver cancer. J Hepatol. 2013;59:1255-63.

119. Zhang L, Sun H, Zhao F, Lu P, Ge C, Li H, Hou H, Yan M, Chen T, Jiang G, et al. BMP4 administration induces differentiation of CD133+ hepatic cancer stem cells, blocking their contributions to hepatocellular carcinoma. Cancer Res. 2012;72:4276-85.

120. Larsen DH, Poinsignon C, Gudjonsson T, Dinant C, Payne MR, Hari FJ, Rendtlew Danielsen JM, Menard P, Sand JC, Stucki M, et al. The chromatinremodeling factor $\mathrm{CHD} 4$ coordinates signaling and repair after DNA damage. J Cell Biol. 2010;190:731-40.

121. Pan MR, Hsieh HJ, Dai H, Hung WC, Li K, Peng G, Lin SY. Chromodomain helicase DNA-binding protein 4 (CHD4) regulates homologous recombination DNA repair, and its deficiency sensitizes cells to poly (ADP-ribose) polymerase (PARP) inhibitor treatment. J Biol Chem. 2012;287:6764-72.

122. Nio K, Yamashita T, Okada H, Kondo M, Hayashi T, Hara Y, Nomura Y, Zeng SS, Yoshida M, Sunagozaka H, et al. Defeating EpCAM (+) liver cancer stem cells by targeting chromatin remodeling enzyme CHD4 in human hepatocellular carcinoma. J Hepatol. 2015;63:1164-72.

123. Qian M, Wang DC, Chen H, Cheng Y. Detection of single cell heterogeneity in cancer. Semin Cell Dev Biol. 2016. doi:10.1016/j.semcdb.2016.09.003. [Epub ahead of print]

124. Sun YF, Xu Y, Yang XR, Guo W, Zhang X, Qiu SJ, Shi RY, Hu B, Zhou J, Fan J. Circulating stem cell-like epithelial cell adhesion molecule-positive tumor cells indicate poor prognosis of hepatocellular carcinoma after curative resection. Hepatology. 2013;57:1458-68.

125. Lu B, Huang X, Mo J, Zhao W. Drug Delivery Using Nanoparticles for Cancer Stem-Like Cell Targeting. Front Pharmacol. 2016;7:84

126. Wang X, Low XC, Hou W, Abdullah LN, Toh TB, Mohd Abdul Rashid M, Chow EK. Epirubicin-adsorbed nanodiamonds kill chemoresistant hepatic cancer stem cells. ACS Nano. 2014;8:12151-66.

127. Wang Z, Tan J, McConville C, Kannappan V, Tawari PE, Brown J, Ding J, Armesilla AL, Irache JM, Mei QB, et al. Poly lactic-co-glycolic acid controlled delivery of disulfiram to target liver cancer stem-like cells. Nanomedicine. 2016. doi:10.1016/j.nano.2016.08.001. [Epub ahead of print]

128. Maude SL, Frey N, Shaw PA, Aplenc R, Barrett DM, Bunin NJ, Chew A, Gonzalez VE, Zheng Z, Lacey SF, et al. Chimeric antigen receptor T cells for sustained remissions in leukemia. N Engl J Med. 2014;371:1507-17 
129. Lee DW, Kochenderfer JN, Stetler-Stevenson M, Cui YK, Delbrook C, Feldman SA, Fry TJ, Orentas R, Sabatino M, Shah NN, et al. T cells expressing CD19 chimeric antigen receptors for acute lymphoblastic leukaemia in children and young adults: a phase 1 dose-escalation trial. Lancet. 2015;385:517-28.

130. Gao H, Li K, Tu H, Pan X, Jiang H, Shi B, Kong J, Wang H, Yang S, Gu J, Li Z. Development of $\mathrm{T}$ cells redirected to glypican-3 for the treatment of hepatocellular carcinoma. Clin Cancer Res. 2014;20:6418-28.

131. Deng Z, Wu Y, Ma W, Zhang S, Zhang YQ. Adoptive T-cell therapy of prostate cancer targeting the cancer stem cell antigen EpCAM. BMC Immunol. 2015;16:1.

Submit your next manuscript to BioMed Central and we will help you at every step:

- We accept pre-submission inquiries

- Our selector tool helps you to find the most relevant journal

- We provide round the clock customer support

- Convenient online submission

- Thorough peer review

- Inclusion in PubMed and all major indexing services

- Maximum visibility for your research

Submit your manuscript at www.biomedcentral.com/submit
Biomed Central 